QUADERNS DE FILOSOFIA VOL. VII NÚM. I (2020): 47-78

eISSN: 234 I-3042 DOI: IO.7203/QFIA. 7.I.I7776

Ana L. Batalla ${ }^{1}$

Universitat de València

\title{
El gènere del testimoniatge i testimoniar el gènere
}

\author{
The genre of testimony and to testify the gender
}

Resum: Aquest article té com a objectiu apropar-nos al gènere del testimoniatge, tot indicant els principals objectius que persegueix i el contingut que transmet. La metodologia que es proposa per a aquest apropament és butleriana, de manera que es farà una lectura de la nova ontologia del cos que proposa Butler com a forma d'entendre el gènere als camps de concentració i d'extermini, i per veure com s'utilitzaren els estereotips de gènere per danyar l'autoimatge dels deportats als Lager. Veurem, així, no només com el gènere impregna la manera de testimoniar, sinó també com atendre-hi de manera acurada.

Abstract: This paper intends to present the genre of testimony by sketching its fundamental purposes as well as the sort of content that it typically conveys. The approach is inspired in Butler's theoretical framework. I will thus use the new ontology of the body that she proposes to understand the role of gender in concentration and extermination camps. I will show, for instance, how gender stereotypes were used to deteriorate the deportee's self-image in the Lager. We will thus elucidate not only how gender can be testified but also the conditions under which we may genuinely listen to it.

Paraules clau: testimoniatge, gènere, camp de concentració, Judith Butler.

Keywords: testimony, gender, concentration camp, Judith Butler.

${ }^{1}$ Aquest escrit és fruit de la investigació realitzada en el marc del projecte Auto-coneixement, responsabilitat moral i autenticitat (FFI2016-75323-P), finançat pel Ministeri d'Economia, Indústria i Competitivitat, i gràcies al finançament rebut per part de les ajudes per a la Formació de Professorat Universitari (FPU16-01447), finançades pel Ministeri de Ciència, Innovació i Universitats. 


\subsection{A què respon}

La segona meitat del segle xx s'ha conegut com "l'era del testimoni" per part d'historiadors com Annette Wieviorka, ja que arran de la Primera Guerra Mundial es donà un creixement exponencial dels testimoniatges de les víctimes que es negaven a continuar acceptant que la història fóra escrita pels vencedors. Fou amb la Segona Guerra Mundial i l'esdeveniment que canvià la visió de l'ésser humà en la societat occidental, Auschwitz, ${ }^{2}$ que el testimoniatge prengué una rellevància desconeguda fins al moment. ${ }^{3}$ Els primers textos que tenim pertanyen als jueus que ja en el gueto, especialment en el de Varsòvia, se n'adonaren de la importància que tenia crear un arxiu on quedara palesa la seua forma de vida, les tradicions, la llengua, ja que el nazisme tenia per objectiu acabar amb la seua comunitat, sense deixar rastre en el futur de la seua existència. ${ }^{4}$

Posteriorment, un gran nombre de supervivents dels guetos i els camps de concentració i extermini nazis consideraren com un imperatiu o un deure moral testimoniar en nom d'aquells que ja no podien fer-ho i començaren a escriure el seu testimoniatge només tornar; Primo Levi, Charlotte Delbo o Robert Antelme són exemples d'aquestes primeres obres escrites. ${ }^{5}$ Fou a partir dels anys setanta del segle xx que començà el projecte de recollir de forma siste-

\footnotetext{
${ }^{2}$ Seguint allò defensat per G. Agamben (2000) i J. F. Forges (2006), entre d'altres, utilitzaré el topònim Auschwitz per referir-me al sistema concentracionari nazi, que inclouria tant els camps de concentració com els camps d'extermini, i tractaré d'evitar els terme Holocaust o Shoà per les connotacions religioses que tenen. El que m’interessarà veure als testimoniatges serà el que poden tenir en comú amb tot ésser humà. L'anàlisi que vull dur a terme és antropològica i filosòfica, de manera que evitaré les explicacions religioses d'Auschwitz.

3 "Els testimoniatges eren ja innombrables als anys cinquanta. Ens trobem avui davant una massa de testimoniatges - centenars de milers, pot ser-, dels quals no existeix cap bibliografia exhaustiva. Cap altre esdeveniment històric, ni la guerra del 14-18 que marcà al començament del testimoniatge en massa, ha suscitat un moviment tan considerable i que s'extenga en una durada tal, de manera que cap investigador no pot presumir de controlar aquest conjunt" (WIEvionKA 2013, 12, la traducció és meua).

${ }^{4}$ Els arxius dels guetos foren essencials en aquest sentit, ja que se n'adonaren aviat que la massacre suposava l'abolició de la yiddishkeit: "Tot allò que permet a l'home arrelar-se: la seua llengua, la seua història, el seu territori, la seua xarxa de sociabilitat, i que constitueix habitualment els marcs de la memòria, ha estat esborrat" (WieviorKa 20I3, 46, la traducció és meua).

${ }^{5}$ Aquests testimoniatges, però, no trobaren un espai adequat per a ser escoltats, de manera que obres com la de Levi trobaren grans dificultats per ser publicades i no fou fins a finals dels anys cinquanta — quan ja el temps havia permès una elaboració dels fets, i gràcies al procés d'Eichmann en 1961, que va emergir en les societats occidentals la figura del testimoni- que aquests testimoniatges foren reeditats $i$ començaren a rebre el reconeixement que tenen actualment.
} 
màtica testimoniatges audiovisuals ${ }^{6}$ que se sumaren a les obres escrites, donant pas així a una democratització dels actors de la història.

El projecte moral de donar testimoniatge per aquells als que se'ls ha arravatat la vida i, amb ella, la veu per donar compte de la seua tragèdia, és quelcom comú als supervivents dels diferents sistemes concentracionaris que es crearen al segle xx, d'entre els quals tindrem en compte fonamentalment el sistema nazi, però també estaran presents, en menor mesura, el soviètic i els dels països del Con sud: Xile, Argentina i Uruguai.

El fet essencial que tindran en comú tots els textos concentracionaris és la condició de testimoni dels seus autors. D’aquesta condició dóna compte Giorgio Agamben amb les dues paraules llatines que s'utilitzaven per referir-se a la figura del testimoni: testis "hace referencia al testigo en cuanto interviene como tercero en un litigio entre dos sujetos" (2000, 156) i superstes "es el que ha vivido hasta el final una experiencia y, en tanto que ha sobrevivido, puede referírsela a otros" (ídem). Amb aquestes dues concepcions de la figura del 'testimoni' s'explica per què la veu dels supervivents està especialment autoritzada per la societat per reclamar justícia per les víctimes i pel seu record, ja que han compartit aquesta experiència conjuntament fins al final dels seus dies. Els textos concentracionaris responen, doncs, a l'autoritat del qui ha viscut una experiència extrema i es compromet amb l'imperatiu del record i el compromís amb les víctimes que no sobrevisqueren. Aquests textos s'escriuen per donar veu als que ja no la tenen ni podran tenir-la, perquè la seua experiència perdure en el temps:

El único que puede testimoniar es el testigo, que habla con los desaparecidos (en su memoria afectiva), por ellos (en su comunicación con los otros) y de ellos (sobre todo en el último tramo de sus vidas) (STrejilevich 2019, 35).

Aquesta tasca que el supervivent sovint pren com un deure moral vers els desapareguts o els enfonsats, si utilitzem la terminologia de Primo Levi, ${ }^{7}$ té diverses vessants que és fonamental tenir en compte: al mateix temps que es

6 "És a finals dels anys setanta, després de l'emoció i les controvèrsies que seguiren als Estats Units, com a França i Alemanya, la difusió de la telenovel-la Holocaust, que apareix per primera vegada la idea que cal recollir sota la forma audiovisual el testimoniatge del que els americans anomenaren a partir d'aquell moment survivors, supervivents, que defineixen com tots els jueus que van viure sota el domini nazi, al Tercer Reich o als països que l'Alemanya nazi ocupà, i que escaparen a la Solució Final" (Wieviorka 20I3, 129, la traducció és meua).

${ }^{7}$ Primo Levi defensà en la seua trilogia sobre Auschwitz que tots els homes del Lager es podien agrupar sota dos grups clarament diferenciats: els enfonsats i els salvats, entre aquells que havien seguit el pendent fins al fons, s'han convertit en Muselmänner i tenen ben a prop la mort, i aquells que seguiren diferents i tortuosos camins fins a la salvació. 
tracta de fer justícia a les víctimes que han sofert la injustícia radical que suposaren els camps o altres experiències del dany com la tortura o l'exili forçat, el testimoniatge també té un objectiu prospectiu: conscienciar a la població per tal que aquests danys no es reproduïsquen, perquè estiguen alerta davant d'actes d'odi, menyspreu i violència, per tractar d'impedir que es propaguen, per intentar aprendre de la història fins on duen aquests camins i com és de perillós és recórrer-los.

El testimoniatge és un mitjà de transmissió de la memòria activa: tracta de donar veu a les víctimes per fer que perduren en el temps, que la seua experiència i el dany que visqueren tinga presència a la societat que els va infligir tal ferida. En aquells contextos en què la veu del botxí autoritari segueix tenint presència, es tracta de trencar el monòleg que aquest pretén imposar. En el context en què s'escrigueren els primers testimoniatges del camps nazis, es tractava d'evitar que els SS tingueren raó amb allò que deien als deportats: podeu dir el que vulgueu, perquè ningú fora us creurà; i per això tractaren d'eliminar també les proves del que havia succeït. Però la qüestió fonamental a què s'enfronten les víctimes és que la resta de la gent, els que podríem anomenar espectadors, miren cap a un altre costat, són sordmuts voluntaris, en paraules de Levi. Els supervivents són una figura incòmoda dintre de la societat perquè revelen la profunditat de l'horror que és capaç de crear l'ésser humà.

Donar espai a una pluralitat de veus d'entre aquells que sobrevisqueren és una forma de compromís amb les víctimes, d'apertura a l'escolta de les seues experiències personals, de tractar de fer justícia a la singularitat de cada experiència i de donar compte en la mesura del possible de la seua heterogeneïtat. La veu del testimoni és sempre singular i col-lectiva al mateix temps, ja que narra la seua experiència del dany particular però sempre tenint present el silenci d'aquells que no pogueren tornar, silenci que es converteix almenys en un fil de veu amb el testimoniatge. Aquesta pluralitat de veus fa palès el valor normatiu i epistèmic del testimoni: deixar espai perquè la veu de diferents víctimes tinga presència en l'opinió pública reforça el pes del conjunt d'aquestes, perquè en haver-hi elements comuns entre els diferents testimoniatges, alguns que es repeteixen, altres amb aires de família, tenen un valor normatiu que és molt més difícil de negar que si aquestes veus es redueixen a una sola.

La narració de l'experiència viscuda pels supervivents d'experiències límit del dany majoritàriament té com a punt de partida fer justícia a les víctimes i denunciar els botxins perquè la resta de la societat se n'assabente d'allò que succeí, però també respon a una necessitat de narrar i de donar forma per escrit al que va viure personalment, com una forma d'exoneració interior, podríem dir. D'aquesta necessitat de narrar dóna compte Primo Levi quan afirmava ser mogut per un impuls immediat i violent (Levi 20 I I, 25), quelcom que el duia 
a explicar a tothom que trobava pel carrer i al transport públic que usava diàriament allò que havia viscut a Auschwitz. ${ }^{8}$ Narrar l'experiència traumàtica que havia viscut li ajudava a donar un sentit a la història personal, a compartir-la amb altres, a incorporar aquesta experiència al curs de la vida, $i$ a començar a donar-li forma per escrit, primer en forma poètica i després en la forma narrativa que inicià amb Se questo è un uomo.

Pel que fa a la necessitat de donar forma per escrit a tal experiència, Leonor Arfuch explica en La vida narrada. Memoria, subjetividad y politica com les narratives del jo donen forma a allò que en principi és efímer: la nostra constitució com a subjectes. La memòria, com a forma d'elaboració d'experiències passades, i especialment quan es tracta d'experiències traumàtiques, posa en joc la capacitat performativa del llenguatge que, amb el desafiament que suposa tornar a dir, permet tornar a viure i d'alguna forma donar sentit a la història personal. Seria així com la narració com a treball de dol ens mostraria la dimensió formativa i ètica de la memòria. Aquesta narrativa possibilita transitar des del jo al nosaltres, d'allò individual a allò col-lectiu, fet que permet al testimoni sentir-se part d'un tot i recuperar el vincle social que el sistema concentracionari busca trencar.

El testimonio también es marcadamente relacional: no existe sin escucha, el "otro" atento es quien lo posibilita. Al sobreviviente que cuenta su historia le importa ser cré́do porque habla de un sufrimiento colectivo que se ignora o se evita enfrentar. Al contar su experiencia, insisto, busca reestablecer el vínculo con una sociedad de la que fue aislado y a la que aspira volver, por lo que le urge nombrar el daño. Le importa que lo que rememora sea admitido como real, aunque solo pueda ofrecer retazos de memorias olvidadizas (STREJILEVICH 2019, 39).

És així com podem veure el testimoniatge com un acte de resistència en dos sentits: en primer lloc, el fet de prendre la paraula és ja una forma de lluitar contra el silenci que imposaven els botxins als camps (especialment en el cas de la tortura) i una forma de recuperació de l'espai social del que l'individu fou expulsat;" com diu Strejilevich: "Relatar desde la subjetividad

${ }^{8}$ La necessitat de Levi d'explicar a tothom el que havia viscut, la gestació de la seua obra escrita i la seua vocació com a educador de les generacions més joves l'he explicada detingudament en Batalla (2017)

${ }^{9}$ Com diu Nora Streijlevich: "Los testigos, en suma, procuramos volver a la sociedad de la que fuimos expulsados y marginados para cuestionar, desde el testimonio - razonamiento emocional o emoción pensada-, ese acontecimiento inaceptable que nos rebela y nos mueve a un accionar donde la palabra cumple una función esencial: nombrar (con pasión) lo que se quiso borrar (con frialdad)" (2019, 52). 
deconstruye el idioma del horror, lo pone en evidencia, lo desafía, lo deshace" (2019, 36). El subjecte reescriu la ferida que suposaren els camps per a la seua vida, reelabora la seua relació amb aquesta ferida, i d'alguna manera nega així la cosificació que pretenien els botxins gràcies al llenguatge i al poder de comunicació d'aquest, tant a nivell informatiu com emocional.

A més dels objectius que ja hem vist: fer justícia a les víctimes, ser prospectiu, donar forma per escrit, ser un acte de resistència i recuperació el vincle social, la creació d'una memòria que quede present per sempre serà fonamental per als testimonis. Aquesta atemporalitat del testimoniatge escrit és rellevant pel fet que molts dels supervivents tingueren la mateixa por, especialment quan començaren a envellir: la por d'oblidar tot allò que els succeí, l'angoixa d'oblidar als companys que moriren al camp, la incertesa de si el que recordaven era el que havia passat o si estaven enganyant-se i fallant en el seu deure de testimoniar en nom dels companys que no tornaren. Aquesta angoixa es fa palesa en molts dels testimoniatges i mostra la necessitat de crear una memòria escrita que no permeta l'oblit dels companys. Es tracta d'una memòria, doncs, que al mateix temps que serveix com a conscienciació social per donar a conèixer els fets i com es podia viure i sobreviure al sistema concentracionari, serveix a les pròpies víctimes per mantenir viu el record, com una forma de lluitar contra l'angoixa de l'oblit. ${ }^{10}$

Una manera de mantenir viu el record que destaca en els testimoniatges de dones supervivents és la de dedicar capítols sencers dels seus escrits a rememorar l'experiència d'algunes companyes, com va fer Charlotte Delbo en la seua trilogia Auschwitz et après, o fins i tot escrigueren un llibre de memòries de la seua companya més íntima, com Margarete Buber-Neumann: Milena, Kafkás freundin. Un altre cas paradigmàtic d'açò és Liana Millu, qui escrigué un testimoniatge titulat Il fumo di Birkenau en el que cadascun dels sis capítols està dedicat íntegrament a una de les seues companyes que van morir al camp.

\subsection{El contingut que transmet}

La possibilitat de donar compte de com es podria viure en les circumstàncies que imposava el camp és essencial per veure una vessant dels camps que tradicionalment no ha sigut treballada. Tal com deien Marceline

${ }^{10}$ La relació de tot testimoniatge amb l'oblit i el record dels Lager és molt problemàtica, ja que aquests records són traumàtics, els angoixen i torturen sempre, fins i tot dècades després, però oblidar seria per a molts d'ells més angoixós encara, perquè el deure ètic de recordar als companys $\mathrm{i}$ evitar que quelcom similar es done al futur prima per damunt de la suposada tranquil.litat d'esperit que podria suposar l'oblit. 
Loridan-Ivens ${ }^{11}$ i Imre Kertész, ${ }^{12}$ el que ells volen és transmetre com era la quotidianitat dels camps, com es podia viure allí amb els companys, convivència que tenia moments que fins i tot podrien qualificar-se de felicitat.

El testimoniatge dels matisos possibles de l'experiència de la quotidianitat als Lager pot considerar-se un acte de resistència perquè es nega a establir com únic element de la narració l'horror i la deshumanització a què foren sotmesos als camps. És clar que als camps de concentració estan presents tota mena de mecanismes de deshumanització i despersonalització, i en el cas del sistema nazi, l'exterminació genocida és quelcom del que cal donar compte als testimoniatges, però també es revela fonamental poder deixar espai per als elements de la quotidianitat que permetien defugir aquests mecanismes que pretenien eliminar la identitat dels deportats: "Aunque los testigos describan el campo como el enclave de crueldad y de muerte que fue, también los detenidos crearon espacios de cobijo" (STrejILEVICH 20I9, 64). I són aquests espais de refugi o protecció els que destaquen els testimoniatges de supervivents com Kertész, Loridan-Ivens, Delbo, Buber-Neumann i Millu, entre molts altres. Aquests espais permetien una solidaritat amb les companyes que prenia moltes formes diferents, des de la creació de xarxes afectives interpersonals, a l'humor o l'amistat.

Ara bé, la qüestió de com és possible transmetre l'experiència de situacions límit com les dels Lager nazis no deixa de ser problemàtica: mentre que alguns supervivents utilitzaren el llenguatge cinematogràfic per donar compte de què suposà sobreviure, com va fer Marceline Loridan-Ivens en La petite prairie aux bouleaux, altres han advocat per l'escriptura poètica, com Paul Celan, i d'altres per la narrativa, siga aquesta una descripció el més fidel als fets possible, com va fer Mercedes Núnez, o una narració més ficcional,

11 "Com Imre Kertész, jo vull dir: 'Voleu sentir l'horror? Això us agrada? Eh bé, vaig a contar-vos un altra cosa'. Perquè la gent no ens demanen com hem viscut durant tot aquest temps allà. Ens demanen: 'Conta’m els horrors. Et pegaven? Com? Què et feien?'. L'única pregunta de la meua mare era: 'Has estat violada?'. L'única cosa que us interessa és l'horror. Però ja és suficient. No compreneu res, no voleu comprendre, no feu l'esforç. I l'horror que us descric, no és l'horror, per a vosaltres, perquè això us obsequia. Tant parlar-vos de la felicitat als camps.

Com va dir també Kertész: 'Allà també, entre les xemeneies, als intervals del sofriment, hi havia alguna cosa que s'assemblava a la felicitat"” (Loridan-Ivens 2008, 110, la traducció és meua).

12 "Mi madre me estaría esperando y seguramente se pondría muy contenta de verme, la pobre. Me acordé de que ella quería que yo fuera arquitecto, médico o algo así. Seguramente así sería, como ella deseara, puesto que no existía ninguna cosa insensata que no pudiéramos vivir de manera natural, y en mi camino, ya lo sabía, me estaría esperanzo, como una inevitable trampa, la felicidad. Incluso allá, al lado de las chimeneas había habido, entre las torturas, en los intervalos de las torturas algo que se parecía a la felicidad. Todos me preguntaban por las calamidades, por los 'horrores', cuando para mí ésa había sido la experiencia que más recordaba. Claro, de eso, de la felicidad en los campos de concentración debería hablarles la próxima vez que me pregunten. Si me preguntan. Y si todavía me acuerdo" (KeRTÉSz 2006, 262-3). 
com Imre Kertész, qui digué que el camp de concentració sols és imaginable com a literatura, no com a realitat. Cada supervivent tractà de donar compte de l'experiència traumàtica que havia viscut de la forma que més se li adeia personalment, de manera que un estudi que pretenga donar compte de la complexitat de l'experiència del dany als Lager ha de deixar espai perquè un diàleg entre els supervivents siga possible, evitant donar per tancada cap de les preguntes que ens podem fer al respecte, ja que sempre ha de quedar espai per a noves veus, noves experiències que poden fer trontollar allò que consideràvem conclòs. Es tractaria de fer un escrit coral,,$^{13}$ on estiga present la màxima diversitat de memòries possible, defugint en una mesura raonable el cànon preestablert i permetent la irrupció d'altres veus: tant l'experiència d'homes com de dones de diferents nacionalitats, creences i cosmovisions, formació i edats distintes, amb diferents llengües maternes i amb diferents relacions amb el seu origen nacional.

Aquesta apertura a escoltar diferents veus considere que és una necessitat epistèmica en aquest context, perquè limitar l'estudi a supervivents d'un sol gènere o escrits en una mateixa llengua redueix molt la visió que es transmet. Existeixen moltes monografies i tesis doctorals sobre autors concrets, per exemple, només sobre Primo Levi podem trobar tesis doctorals com ara La inextinguible memoria de las cenizas, de Secundina Roscales Sánchez, o Narración, escritura y memoria: en torno a Primo Levi y la experiencia concentracionaria, de Inés Valle Morán; llibres que tracten conceptes fonamentals com La pregunta por el hombre. Primo Levi y la zona gris, de David Galcerà i Ulises en Auschwitz, de François Rastier; milers d'articles acadèmics i un llarg etcètera. Sense menysprear en cap cas l'esforç i la rellevància d'aquestes obres per comprendre en profunditat determinades experiències, crec que

${ }^{13}$ Un exemple paradigmàtic d'escrit coral és Una sola muerte numerosa de Nora Strejilevich. Aquesta decisió estètica tenia un gran significat ètic i social per a l'autora: "Era, éramos, huérfanos culturales y existenciales y nos buscábamos entre las páginas de nuestros libros en primera persona del plural. Había perdido compañeros, familia, geografía, lengua, pertenencias, fotos, parientes, amigos, significación. Habíamos perdido. El tejido social se había resquebrajado, había sido procesado por un engranaje sangriento y flotábamos como átomos disparados de su órbita. Los más afortunados éramos refugiados; los nada afortunados eran cuerpos en tumbas NN, o en el Río de la Plata, o más allá. Por eso me urgía escuchar a otros: quería recuperar una comunidad, aunque fuera de damnificados. En 1987 busqué a mis pares (otros testigos de la época) y les pedí que me contaran cómo habían sobrevivido, qué recuerdos los atrapaban. De sus palabras brotaba la intensidad que tiene la primera rememoración en voz alta. El renacer de un tramo casi espectral de la vida tiene un extraño brillo. Es un alivio contar y ser escuchado. En este recorrido que llevé a cabo por las evocaciones de otros, cada historia iluminaba más pliegues de la catástrofe y me revelaba que nuestras voces eran ecos de una sola muerte numerosa. La lucha por un mundo mejor, como se decía entonces, había sido arrojada al mar. Éramos un coro que, al susurrar la pesadilla, revelaba la devastación de un universo. En nuestra memoria navegaban cuerpos, ausencias, lágrimas, risas, derrota, resistencia" (STREJILEvich 20I9, 283-4). 
una perspectiva que ens permeta comprendre la complexitat de l'experiència del dany que suposaren els camps sols és possible aconseguir-la tenint en compte una pluralitat de veus tan àmplia com siga possible, ja que no és el mateix llegir a Ruth Klüger, que era una adolescent quan va ser deportada a Theresienstadt, que a Jean Améry, que era ja un home adult amb una gran formació acadèmica.

\section{UNA METODOLOGIA BUTLERIANA}

La metodologia de treball que considere més adient per dur a terme una anàlisi acurada del testimoniatge està fonamentada en la possibilitat de transmissió del record donada per la vulnerabilitat comú a tots els éssers humans i l'apertura dels cossos d'una forma general i, en particular, quan narren una experiència traumàtica. La posició de l'investigador ha de ser la de transmetre el testimoniatge d'altres cossos i el record del sofriment dels mateixos mitjançant l'escolta atenta a la veu de les diferents víctimes i al seu relat. Això és, mitjançant el reconeixement de la vulnerabilitat, l'apertura als altres i l'empatia del cos, amb els conceptes de Butler que analitzaré a continuació.

La nova ontologia del cos de Judith Butler té per element fonamental o punt de partida la vulnerabilitat ${ }^{14}$ del cos de tot ésser humà. A partir d'aquest concepte de la vulnerabilitat del cos, que es manifesta obertament per a la societat nord-americana a partir dels esdeveniments de l'11 de setembre de 2001, Butler va traure a colllació el concepte de "vida" i es va plantejar la distinció entre vides valuoses $\mathrm{i}$ intel-ligibles, que mereixen dol i ser plorades quan es perden, i vides precàries que no mereixen dol. És a dir, Butler revela la separació que la mentalitat pròpia de la maquinària de guerra fa entre les vides que considera valuoses i dignes de ser viscudes i aquelles que, en tant que es consideren sense valor i que la seua pèrdua no mereix ser plorada, es podria afirmar que mai es van arribar a considerar com a vertaderes vides. És així com podríem començar a pensar l'ontologia de la vulnerabilitat a partir de l'experiència de pèrdua i de dolor, i al mateix temps, pensar com es regulen les disposicions afectives en contextos socials no bèl-lics mitjançant la distribució desigual del dol.

Cal destacar, per evitar malentesos, que la vulnerabilitat no l'hem d'associar exclusivament a la possibilitat de ser ferits, de ser víctimes del dany. Està relacionada amb la nostra apertura als altres, amb la receptivitat cap a tot allò que ens envolta: els altres individus i el món, el medi. Partint d'aquesta

${ }^{14}$ Amb el terme vulnerabilitat s'està traduint ací "precariosuness", concepte que més endavant introduiré detingudament. 
concepció, Butler proposa una ontologia de la vulnerabilitat que deixa entreveure, a partir d'aquesta distribució desigual del dol respecte de les víctimes en contextos bèl-lics, com tota comunitat política reconeix certes vides com a valuoses i d'altres com si no meresqueren la pena de ser viscudes. És així com la categoria de cossos políticament exclosos o abjectes pren rellevància. L'abjecte és aquell individu el cos del qual està fora d'allò reconegut com a legítim per una societat, de manera que és inintel-ligible per als subjectes. Aquests estan constituïts a força d'exclusió. Però aquesta exclusió és essencial perquè puga emergir el subjecte i, amb aquest, establir l'àmbit d'allò normatiu. Els abjectes formaran part de tota societat perquè són necessaris per a la constitució dels subjectes. Sense els uns, no existirien els altres. D'aquesta forma, els cossos abjectes, al mateix temps que han de ser exclosos, representen l'exterior a partir del qual la normativitat i la subjectivitat dels cossos normatius és possible. L'exterioritat dels abjectes és necessària, aleshores, al mateix temps com a constitutiva de la normativitat a la qual no pot pertànyer i com una amenaça constant a aquesta.

És interessant destacar que aquests cossos abjectes ho són des de dues perspectives diferents però íntimament relacionades. D’una banda, són cossos inintel.ligibles des d'un punt de vista epistemològic, no es poden reconèixer des de dintre del marc en què està instal.lada la societat, mentre que al mateix temps són cossos il-legítims o inadmissibles des del punt de vista normatiu. Ara bé, no es pot negar que, de fet, existeixen i s'aprehenen justament com a abjectes. És aquesta distinció entre aprehendre i reconèixer una vida la que marca la diferència fonamental entre uns $i$ altres en Frames of war. Mentre que el reconeixement seria una qüestió conceptual, que segueix unes normes imposades pels esquemes d'intel.ligibilitat disponibles en una societat, l'aprehensió mostra que la vida sempre excedeix aquestes normes. L'aprehensió d'una vida implicaria

marking, registering, acknowledging without full cognition. If it is a form of knowing, it is bound up with sensing and perceiving, but in ways that are not always - or not yet—conceptual forms of knowledge. What we are able to apprehend is surely facilitated by norms of recognition, but it would be a mistake to say that we are utterly limited by existing norms of recognition when we apprehend a life. We can apprehend, for instance, that something is not recognized by recognition. Indeed, that apprehension can become the basis for a critique of norms of recognition (BUTLER 2009, 5).

És gràcies a l'aprehensió, doncs, que podem percebre que hi ha vides que no s'estan considerant valuoses, que aquesta exclusió crea cossos abjec- 
tes i que les vides d'aquests són menyspreades tot i que són necessàries per a la formació de la normativitat i, per tant, per a la creació dels subjectes. Aquests últims són recognoscibles, mentre que els abjectes només es possibilita aprehendre, però és precisament aquesta aprehensió la que possibilita - $\mathrm{i}$ fa gairebé inevitable - una crítica de la normativitat del reconeixement per ampliar l'àmbit d'aquesta. És mitjançant l'aprehensió com els subjectes podrien fer-se conscients del seu menyspreu per la vida dels abjectes, aprehendre les seues vides també com a dignes de ser viscudes i, per mitjà de l'ontologia de la vulnerabilitat i l'apertura que és fonamental en aquesta, entendre que hi ha uns altres fora dels que depèn la meua vida: "there are others out there on whom my life depends, people I do not know and may never know. This fundamental dependency on anonymous others is not a condition that I can will away". (ButLer 2004, xii).

Aquesta nova ontologia del cos que proposa Butler es basa, com estem veient, en el fet que tota societat exclou de l'esfera política certs cossos, i s'explica a partir de la distinció que fa en Frames of war entre precariousness i precarity..$^{15}$ La primera és una noció existencial, que afecta a tot ésser humà en tant que el seu cos és vulnerable i necessita de certes condicions materials per sobreviure, mentre que la noció de precarity és política i denota la distribució desigual dels recursos materials disponibles i necessaris per a la vida. El que reivindica Butler amb aquesta distinció és que, mentre que hi ha una precariousness que és comú a tots, constitutiva de què significa ésser humà $\mathrm{i}$ per tant inevitable, la precarity és una qüestió de responsabilitat social i política, de manera que la distribució desigual dels recursos fa que hi haja part de la població empobrida mentre una altra viu luxosament i considera que la vida dels altres no mereix ser viscuda. Aquesta desigualtat en la distribució de la precarity no és necessària, sinó contingent i tot individu se n’ha de fer responsable des d'una comprensió de la precariousness que és comuna a tots. És per això que Butler considera que reconèixer aquesta precariousness i la responsabilitat que du associada, "should take form as concrete social policy regarding such issues as shelter, work, food, medical care, and legal status" (Butler 2009, 13).

Davant el reconeixement de la precarity de l'individu que tinc al davant, hi ha dues opcions: 1) mantenir-se dintre del marc normatiu i arribar a veure com a "naturals" aquestes diferències i desequilibris socials, de manera que els justifique com si foren inevitables, perpetuant així les distincions establertes entre els subjectes polítics i aquells la vida dels quals està situada en zones inhabitables o invivibles de la comunitat política, és a dir, els

${ }^{15}$ Aquests dos conceptes anglesos tindrien la mateixa traducció a la nostra llengua, de manera que utilitzaré els originals en anglès per tractar d'evitar confusions. 
cossos abjectes, o 2) aprehendre la contingència d'aquest desequilibri en el repartiment dels recursos i aprehendre el fet que és força arbitrari que hom forme part dels subjectes, i que aquesta pot ser una situació temporal, ja que es pot passar d'una condició a l'altra si es donen certes condicions que poden excloure a qualsevol. Tots som susceptibles d'ambdues condicions, ja que la frontera entre els subjectes i els abjectes es troba en qüestió en tot moment, és permeable. Sols mitjançant l'aprehensió com a dinàmica que permet subvertir el marc normatiu es podria tractar d'eixir del marc particular en què s'està immers i que du a reconèixer només algunes vides com valuoses. Cal remarcar, però, que l'aprehensió permet subvertir el marc però no fer la revolució, és a dir, permet subvertir allò que és exclòs però acaba creant noves formes d'exclusió, ja que són necessàries perquè continue havent-hi subjectes.

Els marcs normatius són essencials per comprendre el moviment entre inclusió i exclusió, el reconeixement i l'aprehensió. Aquests marcs de reconeixement donen compte del fet que dos individus no es troben mai en un espai neutre, sinó que aquest espai està definit per les normes socials que possibiliten i al mateix temps condicionen l'encontre. Les normes que formen aquests marcs són culturals i socials, i per tant variables, però existeixen en tota societat i són les que dicten els contextos dintre dels quals som capaços de reconèixer o no a certs individus com a subjectes i les seues vides com a valuoses. En casos de contextos bèl-lics, que és explícitament sobre el que reflexiona Butler en Frames of war, aquests marcs són els que operen com a subtext de les imatges o informacions que ens arriben dels conflictes i que ens permeten percebre la precarietat de les vides perdudes però ens impedeixen veure les vides dels enemics com a vertaderes vides, en tant que no es consideren dignes de dol. De manera que, amb l'assassinat de qui era l'enemic, no som capaços de veure una pèrdua, perquè no hi ha una vida recognoscible que ha sigut extirpada.

És en aquest sentit que l'ontologia de la vulnerabilitat assenta les seues bases en el fet que tothom té una vida, siga aquesta considerada més o menys valuosa dintre dels marcs de reconeixement en què es troba, i que per tant tota mort hauria de ser digna de dol. Aquesta ontologia ha d'incloure una revisió dels marcs que usem per reconèixer unes vides $\mathrm{i}$ excloure'n d'altres, i que ens tornen indiferents respecte del dolor i la pèrdua dels altres. Com la pròpia Butler diu: "specific lives cannot be apprehended as injured or lost if they are not first apprehended as living" (BUTLeR 2009, 1), de manera que cal posar en dubte el marc epistemològic i moral en què estem immersos, ja que aquest està políticament saturat, mai no és neutre: sempre és sospitós. 
If we are to make broader social and political claims about rights of protection and entitlements to persistence and flourishing, we will first have to be supported by a new bodily ontology, one that implies the rethinking of precariousness, vulnerability, injurability, interdependency, exposure, bodily persistence, desire, work and the claims of language and social belonging (BUTLER 2009, 2).

Aquesta nova ontologia corporal és la que ens permet reconèixer la vulnerabilitat dels cossos, com estem veient, la precariousness comuna i la distribució desigual de la precarity, i així donar compte de la interdependència que ens constitueix en tant que individus que poden ser ferits i la supervivència dels quals està sempre en mans dels altres. ${ }^{16}$ L'individu és dependent dels altres, d'allò que la resta vulguen fer d'ell, ja que vivim socialment i això implica estar íntimament vinculat al medi i a qualsevol altre individu. Som dependents i la nostra vida és precària, és a dir, es recolza "on social and political conditions, and not only on a postulated internal drive to live" (Butler 2009, 21). Però aquesta precarietat no pot ser pròpiament reconeguda, sinó que només es pot aprehendre o captar. I aquesta aprehensió, que està situada fora del marc de reconeixement, és la que ens permet veure que els marcs no poden determinar completament allò que podem pensar o captar, de manera que sempre hi ha un afora d'aquest, alguna cosa que excedeix al marc i que ens permet posar en dubte la forma en què comprenem les coses, eixir d'aquesta comprensió ampliant-la i incloent així elements que prèviament estaven exclosos.

Perquè un marc es torne hegemònic ha de circular, això és, ha de reiterar-se per l'espai i el temps, desplaçar-se i trencar el context que li donà origen. Però aquesta reproducció és la que evidència la seua vulnerabilitat, el seu estar sempre en perill de ruptura. És l'estructura mateixa dels marcs, doncs, la que fa que sempre hi haja una possibilitat d'eixir del mateix, que es puga anar més enllà del marc que limita allò que és recognoscible.

Frames are subject to an iterable structure-they can only circulate by virtue of their reproducibility, and that very reproducibility introduces a structural risk for the identity of the frame itself. The frame breaks with itself in order to reproduce itself, and its reproduction becomes the site where a politically consequential break is possible. Thus, the frame functions normatively, but it can, depending on the specific mode of circulation, call certain fields of normativity into question (BUTLER 2009, 24).

${ }^{16}$ Lafirmació de la interdependència dels individus i de la necessitat dels altres per sobreviure la podem veure en les paraules de G. Tillion, supervivent de Ravensbrück "[Ells] no van sobreviure —sent justos- sinó gràcies a unes mans esteses" (Tillion 201 5, 213, la traducció és meua). 
L'aprehensió ens permet anar més enllà i posar en dubte allò que la normativitat del frame presenta com a intel-ligible i valuós, evidenciant quins són els propis límits del marc a causa de la seua necessitat de reiteració. L'objectiu essencial de la crítica per a Butler no és només subvertir el marc per tal d'incloure els que estan exclosos en les normes socials imperants, sinó denunciar com aquestes normes de fet assignen diferencialment el reconeixement i la precarietat. D'alguna manera, ací podríem veure una certa concepció socràtica per part de Butler, ja que considera que si som capaços de veure l'error conceptual que provoca el marc, el rebutjarem. De manera que la feina principal de la filosofia crítica seria desvelar el marc, ficar-lo en evidència perquè es faça vulnerable i trencar, així, amb el que pretén el marc, que és mantenir-se ocult i fer-se passar per "allò natural" o "allò necessari".

Els marcs normatius, a banda de determinar quines vides són valuoses i per tant mereixen ser protegides, regulen els afectes dels individus particulars, limitant així allò que podem sentir respecte dels individus amb què entrem en contacte i quin ha de ser el model d'individu que hem de seguir per continuar sent considerats subjectes dintre d'aquest marc. Açò dóna lloc a diferents exigències ideals que els individus han de perseguir per ser considerats subjectes dintre del marc normatiu, per no ser-ne exclosos. Aquestes exigències, pel fer de ser ideals, són inassolibles, i això crea frustracions als individus que tracten d'assolir-les. Les exigències que introdueix tot marc normatiu són de molts tipus, però les que m’interessa destacar ací són les de gènere, l'ideal que marca el que cal fer per ser considerat una dona o un home "com cal" en el marc en què estem immersos.

En Gender Trouble: Feminism and the Subversion of Identity, Butler argumenta que els enunciats de gènere són els més clarament existencials, és a dir, són aquells que atorguen més existència a l'individu en tant que faciliten el reconeixement per part del marc en què estem immersos. Aquests enunciats de gènere es construeixen en una xarxa de discursos de manera performativa, es van construint per mitjà del poder reiteratiu del discurs per regular i imposar la materialització dels cossos dintre de normes instituïdes socialment, dintre de marcs normatius que determinen com es pot actuar i ser. Els individus, però, no només són passius respecte d'aquestes relacions i forces que els conformen, sinó que també poden ser actius i subvertir la reiteració de les normes quan les repeteixen o citen en els seus actes. És així com es poden anar introduint matisos en la materialització del gènere en cada cos particular, però això sempre suposa una subversió de la norma que se'n surt de l'aspiració a complir les exigències ideals del marc normatiu. Aquesta aspiració, com hem dit, és frustrant perquè no es pot assolir mai, però és el que permet que la resta et reconeguen com subjecte, de manera que sempre es tendeix a assolir aquest ideal, perquè l'amenaça de l'exclusió està sempre present. 
Aquestes exigències ideals de gènere van canviant en cada societat i context concret, ja que les escletxes que es produeixen en cada repetició de la norma permeten la seua variabilitat. Aquestes s'assemblen al que en altres tradicions s'ha anomenat estereotips de gènere: sistemes de valors a partir dels quals els individus es caracteritzen a ells mateixos i als altres i que determinen els conjunts de qualitats i característiques psicològiques i físiques que una societat determinada assigna a homes i dones. ${ }^{17}$ Els estereotips estableixen quins són els models d'home i dona validats socialment i són els esquemes que s'apliquen en la interacció social. Els rols estandarditzats culturalment es basen habitualment en característiques psicofísiques, de manera que haver nascut amb uns òrgans genitals fa que la societat espere de nosaltres una forma de ser i actuar distintiva. Açò confirma la importància del cos i de la materialització d'aquests.

\section{El GÈnERE ALS LAGER}

Com hem dit, aquests estereotips de gènere o exigències ideals del marc normatiu en terminologia butleriana varien al llarg del temps i de la societat que prenguem com a referència. De manera que se'ns imposa remuntar-nos als anys trenta i quaranta del passat segle per veure quins eren els estereotips de gènere dominants; estereotips que ens permetran comprendre alguns elements diferencials de com foren tractats homes i dones als camps de concentració $\mathrm{i}$ extermini i de com visqueren i narraren aquest internament de forma distinta. Aquesta diferència en com visqueren l'internament als camps és explícita en el testimoniatge dels supervivents que tingueren contacte amb l'altre gènere dintre del camp:

Experimentaban, más punzante que ningún otro, el sentimiento de estar mermados en su fuerza y en su deber como hombres, porque no podían hacer nada por las mujeres. Si nosotras sufríamos al verlos desgraciados, hambrientos, desamparados, ellos sufrían todavía más por no estar en condiciones de protegernos, de defendernos, por no seguir asumiendo solos el destino. Sin embargo, las mujeres los habían descargado de su responsabilidad desde el primer momento. Habían intentado aliviarlos de su preocupación de hombres hacia ellas. Querían convencerlos de que, por ser mujeres, no corrían ningún riesgo. Aún creían que la feminidad era una salvaguarda. Ellos sí debían temerse cualquier cosa, pero ellas podían estar tranquilas con respecto a sí mismas. Sólo necesitarían paciencia y valor, dos virtudes de las que se sentían muy seguras porque son virtudes de todos los días.

\footnotetext{
${ }^{17}$ Seguisc en aquesta caracterització a Bernárdez, García y González (2008, 123).
} 
[...] Se las ingeniaban para sernos útiles, buscaban tareas con las que ayudarnos. ¡Pobres! En la miseria material en que se encontraban, no había nada que pudieran pedirles las mujeres. A ellas, en una miseria semejante, les quedaban aún los recursos que tienen siempre las mujeres. Podían lavarles la ropa, arreglarles la camisa, ya andrajosa, que llevaban el día de su detención, cortar las mantas para hacerles zapatillas. Se privaban de parte de su pan para dársela a ellos. Los hombres deben comer más. Cada domingo organizaban en el patio una diversión a la que asistían los hombres, de pie detrás de las alambradas de espino que separaban los dos sectores. Toda la semana trabajaban las mujeres: cosían, ensayaban para el domingo. Cuando la falta de entusiasmo o el mal humor amenazaba con poner en peligro la preparación de la fiesta, siempre había alguna mujer que decía: "Tenemos que hacerlo, por los hombres". Por los hombres cantaban y bailaban; por los hombres aparentaban despreocupación y alegría. Era una interpretación desgarradora. Pero la animación que despertaba conseguía a veces arrastrar incluso a mujeres que sabían de cierto cuán irrisorio era todo (Delbo 2004, II, 10-1).

Cal tenir en compte, però, que aquests estereotips de gènere no afectaven només a les víctimes, que són les que tindrem més en compte en aquesta anàlisi, sinó que hi havia guardians SS a tots els camps, i guardianes, auxiliars SS, als camps específics de dones. Hi ha molts estudis sobre la formació que rebien i els mecanismes de deshumanització que incorporaven per dur endavant el seu dia a dia. En particular, tres obres destaquen per la profunditat del seu anàlisi: G. Sereny, Into that darkness, C. Browning, Ordinary Men i J. Glover, Humanity. Aquestes anàlisis tracten de donar compte de mecanismes com la desinhibició i el distanciament moral, el desdoblament de la identitat, l'eliminació de la pietat mitjançant la reivindicació de la virilitat i la força bruta, la deshumanització i l'embrutiment de l'enemic mitjançant insults, bromes, l'humor negre, i un llarg etcètera.

Destaca el fet que la majoria de les anàlisis estan basades en contextos bèl-lics on els protagonistes són homes. Ara bé, el sistema concentracionari nazi no hauria sigut possible sense els milers de dones provinents de l'Associació de dones del Partit Nazi que reberen formació per ser guardianes dels camps. La majoria d'aquestes es presentaren voluntàriament, ja que procedien dels estrats més baixos de la societat i buscaven un bon treball i l'oportunitat d'un ascens social, perquè com a guardianes tenien uniforme, un bon sou i podien aspirar a ostentar poder, fet que en un altre context hauria sigut impensable. Altres acceptaren el treball com una manera de rehabilitar-se davant del sistema nazi, ja que eren preses comunes del Reich i tenien antecedents criminals. Aquesta fou una de les tres formes possibles en què les dones involucrades en el naci- 
onalsocialisme pogueren participar personalment, segons la classificació de K. Von Kellenbach (2004). Les altres dues opcions que tenien a l'abast foren ser informants, denunciant a les futures víctimes, o sent metgesses i infermeres del programa d'eutanàsia, juntament amb algunes acadèmiques que investigaren sobre la raça. Aquestes dones, però, no deixaven de formar part de la societat tradicional patriarcal que defensava el nazisme, de manera que estigueren sempre subordinades als homes. En particular, les guardianes dels camps eren auxiliars dels SS, de manera que ells sempre tenien l'última paraula i el poder de decisió. Aquestes guardianes foren considerades, en general, com extremadament violentes i cruels, fins i tot més que els homes perquè coneixien de primera mà el que s'esperava de les dones dintre del marc normatiu en què es trobaven i atacaven a aquells elements de l'autoimatge de les deportades que els podien ferir més profundament.

\subsection{L'estereotip femeni als Lager}

La deshumanització i la despersonalització que els botxins dugueren a terme als Lager tingueren en compte els estereotips de gènere, de manera que la violència que utilitzaven tenia elements diferenciadors de gènere. Per exemple, quan arribaven els trens als camps, la primera selecció es feia entre homes, d'una banda, i dones i xiquets, de l'altra, i després entre aquells que eren valuosos per al treball i els que no. Això suposava que eren les dones les que es quedaven amb els fills i havien de prendre l'esgarrifosa decisió de situar-se a la fila de les que podrien treballar i veure com les separaven dels fills per dur-los a les cambres de gas o continuar al seu costat i morir amb ells. Només les dones havien d'afrontar aquesta duríssima decisió, ja que seguint amb els estereotips tradicionals de gènere, les dones són les cuidadores i per tant les úniques susceptibles d'acompanyar els seus fills fins a les últimes conseqüències. És així com les dones es veuen exposades a un tipus de violència psicològica específica que no han de sofrir els pares dels xiquets.

La separació violenta de les dones respecte dels fills quan prenien la decisió de salvar la seua vida a pesar del que suposava per al menut tenia també un altre vessant: la violenta negació de la seua funció com a mares, que era la funció que el discurs nacionalsocialista havia destacat de les dones alemanyes. Lideal de dona nazi destacava el seu paper com a cuidadores i creadores de la llar, i especialment el seu rol com a mares i educadores de les futures generacions alemanyes. Dintre l'organicisme nazi, en què l'individu sols té sentit en tant que peça d'un engranatge, la dona ària té assignat el rol ancestral de guardiana de la llar, havia de ser mare i companya de vida, treball i lluita de l'home, però mai protagonista en aquests àmbits. La seua esfera d'acció és l'àm- 
bit privat (la propaganda identificava el seu espai amb les tres K: Kinder, Küche, Kirche, xiquets, cuina i església) i havien de deixar el seu cos al servei de l'Estat per elevar com més millor l'índex de natalitat. ${ }^{18}$

Essent aquest l'ideal de dona nazi, resulta més evident el dany específic que involucrava la decisió a què es veien obligades les dones deportades amb la selecció només arribar al camp i la separació forçosa dels seus fills, ja que feia palès que se'ls estava negant la seua condició de dones i danyant així la seua autoimatge com a portadores de vida. També aquest dany específic és evident amb els experiments mèdics d'esterilització que es duien a terme als Lager amb les dones jueves. L'esterilització forçada sense anestèsia arribà a cobrar-se moltes vides, ja que no moltes aconseguien sobreviure a la intervenció. ${ }^{19} \mathrm{~A}$ més, els avortaments forçosos van ser habituals en determinat moment històric dintre dels camps i es van practicar experiments mèdics sobre els òrgans genitals femenins amb raigs $\mathrm{X}$.

${ }^{18}$ L'obsessió del nazisme per incrementar l'índex de natalitat els dugué a crear en 1936 el programa Lebensborn, que prescrivia que cada membre de les SS havia de tindre quatre fills, ja fóra dintre o fora del matrimoni. Amb l'objectiu de preservar la raça ària com fóra, crearen llars que donaven refugi a aquests fills il.legítims i a les seues mares, que tenien així protecció, seguretat i suport econòmic. A més, les dones que tenien quatre o més fills eren condecorades amb la Creu de la Maternitat. Elles es consideraven agents de la revolució conservadora que anava a preservar la raça ària. És per això que els anticonceptius i els avortaments eren il.legals per a les dones àries, mentre que els avortaments eren afavorits si eren fruit d'una relació mixta, amb el conseqüent càstig pels qui havien comès aquesta deshonrosa unió.

La lliga de les joves alemanyes (BDM, Bund Deutscher Mädchen) va satisfer el desig (polític o no) de moltes joves de formar part d'una comunitat i tenir amistats duradores. Al mateix temps, aquesta lliga suposà per a algunes el primer escaló per a la filiació al Partit Nazi i per fer carrera dintre del moviment, però sobretot era una forma d'adquirir les habilitats apropiades per a una dona ària. Allí aprenien a ser "com cal" des d'un punt de vista femení: feien exercicis de campanya i pràctiques de tir, eren educades com patriòtiques cuidadores i combatents, i se'ls inculcava un estil de vida saludable i atlètic, evitant floritures com el maquillatge o les sabates de tacó. Eren considerades especialment belles quan estaven embarassades.

${ }^{19}$ L'esterilització forçosa no va afectar només les dones, sinó que també s’aplicà als homes, fent-los perdre així part fonamental de la seua autoimatge. Charlotte Delbo dóna compte d'açò al primer llibre de la seua trilogia Auschwitz et après:

"Esperan delante del barracón. Silenciosos. En sus ojos, un combate entre la resignación y la revuelta. Es necesario que venza la resignación.

Un SS los vigila. Los empuja. Sin que sepamos por qué, de repente se lanza sobre ellos gritando y golpeando. Los hombres permanecen silenciosos, rectifican las filas, colocan las manos junto al cuerpo. No prestan atención, ni al SS ni a sus compañeros. Cada uno está solo consigo mismo.

[...] Han convertido el barracón en sala de radiografías, diatermia, rayos X.

Los hombres son atendidos en nuestro campo por primera vez. El campo de los hombres está más allá. Tiene un revir, cuentan, mejor que el nuestro. Tal vez sólo menos horrible. ¿Por qué los envían aquí? ¿Es que ahora atienden aquí a la gente?

Los hombres siguen esperando. Silenciosos. La mirada lejana y sin color.

Uno a uno, los primeros comienzan a salir. Se visten en el umbral. Su mirada rehúye los ojos de los que esperan. Y cuando podemos verles la cara, entendemos por qué.

Cómo contar el desamparo de sus gestos. La humillación de sus ojos.

A las mujeres se las esteriliza con cirugía" (Delbo 2004, I, 136-7). 
Aquestes pràctiques tenien atemorides a les deportades, que pensaven que estaven ingerint productes químics altament tòxics diluïts en les racions alimentàries. No hi ha proves de què les enverinaren, però el rumor va recórrer els camps, motiu pel qual moltes dones tingueren por de menjar per si l'aliment contenia aquests productes químics, de manera que els processos de malnutrició s'acceleraren, augmentant així la debilitat física de les deportades i els casos d'amenorrea.

La menstruació de les dones al camp és un altre element problemàtic relacionat amb la seua capacitat reproductiva. D'una banda, l'amenorrea que duia aparellada la desnutrició i les condicions de vida angoixants i estressants del camp els feia qüestionar-se si encara serien capaces de tenir fills si alguna vegada aconseguien eixir del camp, això és, posava en dubte la possibilitat d'acomplir un dels requisits per ser una dona "com cal" dintre dels estereotips tradicionals de gènere. $\mathrm{Al}$ mateix temps, però, continuar menstruant dintre del camp podia arribar a ser humiliant, ja que tenir a disposició tovalles íntimes era impensable, de manera que el sagnat es feia evident per a tothom i eren atacades per part dels Kapos per tenir bruta la roba.

De manera íntimament relacionada amb aquesta qüestió es troba la dels embarassos als camps. Les dones que arribaven ja embarassades i eren descobertes a la primera selecció, eren condemnades a les cambres de gas. Les que aconseguien passar desapercebudes o es quedaven embarassades durant el temps que estigueren al camp, a causa de violacions o d'algun trobament casual, havien d'ocultar com fóra aquesta condició per sobreviure elles i el menut, perquè quan eren descobertes eren condemnades a mort $\mathrm{o}$ obligades a avortar, depenent del moment històric i del camp en què es trobaren. La maternitat, doncs, havia de ser ocultada i algunes la consideraren com un mètode de resistència demostrant-se a elles mateixa i a les companyes que els seus cossos encara eren vàlids per engendrar vida $i$ continuar mantenint la comunitat a què pertanyen i que es vol exterminar. ${ }^{20}$ Això va suposar que alguns embarassos continuaren endavant i que tinguem narracions dels mateixos en testimoniatges de supervivents com Liana Millu, qui narra en Il fumo di Birkenau com la seua companya Maria va dur un fill al món. ${ }^{21} \mathrm{El}$ moment del part és compartit

${ }^{20}$ Tal com explica Alicia Ramos: "Los relatos y las memorias de las mujeres también muestran cómo muchas de ellas entendieron que su cuerpo, capaz de engendrar nuevas vidas, era un arma eficaz para hacer fracasar los intentos nazis de exterminio racial. Y así ellas, inermes, se transformaron de víctimas en conspiradoras, poniendo sus cuerpos al servicio de una cruel batalla contra el enemigo: la lucha por la supervivencia de los judíos" (Ramos 20 Io, 267).

${ }^{21}$ L'ambivalència que suposa tenir un fill a unes condicions com les de Birkenau és explícita en l'obra de Millu, qui comença considerant a Maria com una egoista que només pensa en ella, ja que la criatura estava condemnada a mort abans fins i tot de nàixer (2019, 46), però més endavant acaba acceptant que ella probablement hauria fet el mateix, perquè hauria pensat que la guerra ja hauria acabat dintre de nou mesos i tindrien un lloc segur on viure (Millu 2019, 48). 
de manera quasi mística per les companyes del barracó, una espera vibrant i misteriosa que les unia a totes en el fill que Maria anava a tindre, en l'amor i la delicadesa que inspirava a la resta de dones del barracó aquest nadó que, desgraciadament, moriria amb la seua mare hores després del part, quan s'adonaren que faltava una dona al recompte per a la feina.

El dany específic per a l'autoimatge de les deportades en tant que dones és palès, com estem veient, tant amb la frustració violenta de la maternitat com amb l'esterilització forçada i l'ambivalència de la menstruació i l'embaràs, però també té a veure amb la rellevància que tingueren els mecanismes de despersonalització que duia aparellada la incorporació al camp, com el fet que els raparen el cabell, ${ }^{22}$ la vergonya o el pudor d'estar nues davant d'homes i els registres íntims als que eren sotmeses. Però, per sobre de tots aquests danys específicament femenins, cal destacar els abusos sexuals tant per part dels homes com per part de les auxiliars SS o Kapos lesbianes, les violacions sexuals i la creació de bordells als Lager, que tingueren conseqüències a molts nivells per a les víctimes: no només físiques i psicològiques, sinó també polítiques, simbòliques i morals.

El cos femení sempre s'ha tractat com un espai simbòlic de conquesta i dominació, de manera que la violència específica que pateixen les dones pel simple fet de ser-ho té doble significació: política i simbòlica. És per això que les violacions en contextos bèl-lics han estat sempre presents, ja que la dominació sobre el cos femení i la projecció d'aquestes com a possessió masculina permet veure la violació com una deslegitimació i humiliació dels enemics, que no estarien complint amb el seu deure com a homes de defensar a aquelles, més vulnerables, els cossos de les quals els pertanyen. Els Lager no estigueren absents d'aquest tipus de violència, sinó que fins i tot la institucionalitzaren amb la creació de bordells (Sonderbauten) a partir de 1942 a alguns camps. El primer es va crear a Mauthausen i en justificaren la creació dient que així fomentaven la productivitat dels treballadors oferint-los relacions sexuals a aquells que compliren els objectius. Veiem així com l'explotació sexual sistemàtica de les dones es va convertir en un incentiu i un privilegi per a alguns presoners. Generalment, se seleccionaven per a aquests bordells dones joves i sanes, preferiblement d'origen alemany, amb la falsa promesa que així els permetrien abandonar el Lager en sis mesos. Però aquestes promeses es revelaren falses, ja que transcorregut aquest temps, i perquè els homes no s'avorriren de l'incentiu que els oferien, les canviaven per altres dones i les tornaven al seu grup de

${ }^{22}$ El tall del cabell suposà la mutilació de la feminitat per a moltes deportades, un dany profund a la pròpia autoimatge, ja que ara totes són iguals, indistingibles unes d'altres. L'impacte psicològic d'aquest acte suposa la inseguretat $\mathrm{i}$ la vergonya de les víctimes, que interpreten aquest tall del cabell com una violació de la seua integritat corporal i una negació de la seua identitat individual. 
treball anterior. És d'aquesta manera com podem comprendre la profunditat del dany que suposava per a aquestes dones, ja que la vergonya que sentien per haver acceptat prostituir-se s'unia a la culpa i la humiliació d'haver-ho acceptat confiant en la paraula dels SS, que resultà ser falsa.

Every rape is a grave violation of physical and mental integrity. Every rape has the potential to profoundly debilitate, to render the woman homeless in her own body and destroy her sense of security in the world. Every rape is an expression of male domination and misogyny, a vehicle of terrorizing and subordinating women. Like torture, rape takes many forms, occurs in many contexts, and has different repercussions for different victims. Every rape is multidimensional, but not incomparable (Copelon I994, 265).

Cada violació fa trontollar la confiança en el món de la víctima, en la terminologia d'Améry, supervivent d'Auschwitz. La violació destrueix la seguretat del món, el torna un espai inhabitable, fa sentir a la víctima que està completament dominada per l'altre, sotmesa físicament i psicològicament, i això fa que dintre del context dels Lager, la situació de les dones fóra més vulnerable. Aquesta tràgica experiència la podem llegir també en el testimoniatge de Millu, en què dóna compte dels bordells a Birkenau, de com se sentien les dones que pertanyien a aquests i per què eren menyspreades per la resta de companyes que es resistiren a participar-hi. En el cas de què dóna testimoniatge Millu, una companya anomenada Gustine diu que la seua germana Lotti ha mort quan el que ha passat és que ha acceptat formar part del Puffkomando (així s'anomenava el bordell d'Auschwitz). El seu rebuig cap a la decisió de la seua germana era tan intens que es negava a acceptar l'ajuda material que aquesta li feia arribar per mitjà de les companyes i no li va tornar a dirigir la paraula ni la mirada mai més.

Especialment vulnerable era la situació de les dones jueves, ja que la jerarquització a què es veien sotmeses no era només sexual, sinó també racial. Aquesta discriminació interseccional fa que la situació de les dones jueves als camps nazis fóra més vulnerable, ja que la cultura patriarcal dominant i persistent al món jueu va fer que també els propis presoners jueus consideraren que podien exigir sexe a canvi de menjar o altres recursos materials als que ells tenien més facil accés que elles, tant als guetos com als camps. Aquesta violència sexual per part d'altres jueus resultava més traumàtica psicològicament per a les víctimes per la profunda sensació de traïció que els feien sentir. L'acceptació per part d'elles de "favors sexuals" cal entendre-la com un element de violència sexual pel fet que eren les condicions materials en què es trobaven i l'autoconcepció que tenien les dones d'elles mateixes, sense consciència respecte dels drets que podien reivindicar, el que les dugué a acceptar-los. No es pot considerar que, en un context 
així, les dones acceptaren lliurement mantenir relacions sexuals amb aquells que tenien els recursos materials que els podien permetre sobreviure un temps més.

Aquesta forma d'entendre els "favors sexuals" dintre del camp no era, però, la més extensa en aquell moment històric particular, sinó que la resta de presoners solien reprovar aquestes conductes. És per això que, a la vergonya i la humiliació d'acceptar aquests intercanvis, s'ha d'afegir la condemna externa i la por que aquestes relacions es feren públiques. Es comprèn així les dures conseqüències psíquiques i emocionals d'aquestes dones si aconseguien sobreviure. ${ }^{23}$ La vergonya i la culpabilitat per haver acceptat fer aquest tipus de "favors", juntament amb la xacra simbòlica i política que suposa des d'una perspectiva social, les acompanyà després de l'alliberament i va condicionar el seu silenci durant dècades. La invisibilització del dany específic femení als Lager a escala historiogràfica i social ha fet que l'explotació sexual que sofriren aquestes dones fóra silenciada i menyspreada durant molt de temps, en tant que fins a la dècada dels 70-80 del passat segle no començaren a estudiar-se aquests danys ${ }^{24}$ arran de la publicació de Ravensbrück de G. Tillion en 1975 i de Hitler's death camps de K. Freig en 1981. No va ser fins aquest moment que es començaren a tenir en compte les dones com a subjectes històrics i objectes legítims d'estudi les experiències de les quals tenen molt a dir si ens interessa la qüestió de l'ésser humà a Auschwitz. Fins aleshores, els estudis més tradicionals sobre els camps nazis només tenien en compte els testimoniatges d'homes supervivents, aquells que foren reimpresos i revisats i que ocuparen l'espai de pensament, creant així un cànon de referència: ${ }^{25}$ Primo Levi, Viktor Frankl, Élie Wiesel, etc.

${ }^{23} \mathrm{Al}$ respecte, diu Ruth Klüger (I997, 192): "Los torturados y los violados tienen en común el hecho de que el tiempo no borra lo que les ha sucedido y de que, contrariamente a quienes han sufrido por causa de accidente o de enfermedad, han de andar a vueltas toda la vida con lo que hicieron de ellos, para poder superarlo".

${ }^{24}$ L'estudi historiogràic del rol de les dones com a subjectes i agents del canvi social fou un procés que es dugué a terme en quatre moments: "Gerda Lerner [in (1981) The Majority Finds Its Past: Placing Women In History. Oxford: Oxford University Press] refers to the first phase as compensatory history, entailing a random survey of the landscape for any and all women who might have done something 'noteworthy' during a particular period. The second step centers on contribution history, investigating women-specific contributions to stablished practices, policies or events already deemed 'significant' by mainstream (read: malestream) scholars. The third stage yields to a rewriting of the dominant historical narrative, by raising questions as to what we really 'know/ knew', based on the discovery of new sources, new contexts, and a reconfiguration of old plus new variables. The final meta-stage reassesses the broader parameters of history as socially constructed through gender, race and class, along with new forms of female agency" (Mushaben 2004, 149).

${ }^{25}$ En paraules de la filòloga Marina Sanfilippo (20 I , 310): "la imagen de la Shoah que tenemos se basa sobre todo en las memorias de los hombres; el 'canon' de la literatura del Lager ha sido durante mucho tiempo totalmente masculino. [...] Para el lector no especializado, los nombres obligados eran y siguen siendo Primo Levi, Elie Wiesel, Robert Antelme, Jean Améry, Jorge Semprún, Imre Kertész, a los que se añade, como mucho, Anna Frank. Y esta situación se repite no solo en el ámbito literario, sino también en la historiografía”. 
Aquesta historiografia androcèntrica que ha invisibilitzat el dany femení, l'ha ocultat i silenciat, ha fet que la imatge tradicional d'Auschwitz es trobe distorsionada, ja que només ha tingut en compte l'experiència dels homes i l'ha extrapolada com la de l'ésser humà en general. Així, la comprensió que tenim del que suposà Auschwitz és incompleta i sembla menys complexa del que permetria una perspectiva que té en compte l'especificitat del dany infligit tant a homes com a dones segons els estereotips de gènere que estem veient. Aquesta nova perspectiva, iniciada fa unes dècades, té en compte el context concret social i històric, els ideals de gènere que estaven presents, i com això determinà els tipus de danys específics pensats per ferir l'autoimatge que homes i dones tenien d'ells mateixos.

Una lectura d'aquest tipus ens permet comprendre l'ambivalència que aquests ideals tenen, ja que al mateix temps que provoquen que les ferides siguen més profundes perquè afecten directament a allò que ens possibilita ser subjectes en una societat i reconeguts per la resta, també permet dur a terme moviments de resistència que en altres contexts serien impensables. Per exemple, poc després de l'ascens nazi, les dones suposaren que a elles no les danyarien, perquè no estaria ben vist socialment que atacaren dones indefenses, i és per això que foren elles les que acudiren enfront de la policia, els SS i els ajuntaments per protestar pels actes arbitraris que estaven duent a terme contra els seus fills i famílies. A l'inici del segle $\mathrm{xx}^{26} \mathrm{i}$ amb el pas del temps, les dones compaginaren l'estereotip tradicional de protectores de la llar, de qui dóna la vida i la nodreix, amb el nou concepte de dona treballadora que surt de casa per aconseguir els recursos materials necessaris per sobreviure ella i la seua família, i que s'implica activament amb la resistència clandestina portant missatges, instant a altres jueus perquè no pujaren als trens, construint búnquers per als més vulnerables, aconseguint documents falsos per rescatar jueus dels guetos, transportant pólvora, participant del boicot armamentista, etc.

Tots aquests modes de resistència clandestina podien dur-los a terme, com estem veient, perquè els estereotips tradicionals dificultaven que els SS sospitaren de les dones jueves com a elements actius de la resistència. Tots aquests actes eren esperats dels homes, que foren als primers que deportaren de forma massiva als camps i que estaven més vigilats. Fou així com les dones aprofitaren els estereotips de gènere que hem vist anteriorment per participar

${ }^{26} \mathrm{Cal}$ recordar que a principis del segle $\mathrm{xx}$ va tenir força el sorgiment d'un nou tipus de dona a causa de la Primera Guerra Mundial i de la mobilització total de les societats, ja que aquestes hagueren d'incorporar-se al treball (fonamentalment en la indústria, el comerç i els serveis) i participaren en la guerra de forma activa, com a voluntàries en el cas de les dones russes, o en feines d'avituallament de les tropes, els dipòsits de municions, a les fabriques d'armament, etc. Això va suposar la incorporació de les dones a l'espai públic i a la resistència activa, en la qual tingueren un gran paper durant la Segona Guerra Mundial. 
activament en la lluita contra el nazisme. Altres mètodes de resistència que utilitzaren sí que eren més propers a les exigències ideals del marc normatiu i també tingueren gran rellevància per a la supervivència de les dones tant als guetos com als camps, i després de l'alliberament. Aquests mètodes serien la creació d'escoles, el sosteniment afectiu de la família i les amistats, la cura dels altres, la generació de xarxes de suport social, l'establiment de vincles afectius interpersonals sòlids, etc.

Aquests vincles responen en certa manera a l'estereotip de gènere que estableix que les dones han d'estar més a prop dels seus sentiments i emocions, de manera que són capaces de reconèixer la vulnerabilitat comuna a tots els éssers humans de què parla Butler, la precariousness, i com d'interrelacionats estem: necessitem dels altres per sobreviure, i més en contextos en què les condicions materials estan creades per impedir o dificultar greument la supervivència. Les dones foren capaces de reconèixer aquesta vulnerabilitat i crearen xarxes afectives i de suport que els ajudaren a sobreviure dintre del camp, mentre que per als homes va ser més difícil crear-ne, ja que les relacions que ells tendeixen a establir són més fredes o distanciades, de manera que visqueren el seu pas pels camps d'una forma més individualista i solitària. ${ }^{27}$ Arribem d'aquesta manera a la qüestió de com els estereotips de gènere afectaren també la violència específica contra els homes.

\subsection{L'estereotip masculi als Lager}

De la mateixa manera que els estereotips de gènere que caracteritzaven la societat dels anys trenta i quaranta foren tinguts en compte per dur a terme danys específics contra l'autoimatge de les dones, també es buscà danyar l'autoimatge dels homes al Lager. L'atomització de l'individu, l'aïllament social, la sostracció de tot objecte personal, la rutina del barracó i l'obligació de treballar fins a l'esgotament eren comuns, però prenien formes diferents. Per exemple, només els homes eren seleccionats per formar part dels Sonderkommando que, en paraules de Levi, va ser el pitjor que dugueren a terme

${ }^{27}$ Lestereotip de gènere masculí fa que els homes no es permeten tenir gestos de cura amb els altres perquè això trencaria la seua autoimatge i posaria en dubte que puguen ser reconeguts com a subjectes, podrien ser exclosos del marc normatiu i córrer el perill de ser associats amb l'abjecció. Veure com l'ideal regulador ens situa respecte de cert tipus d'actes ens permet comprendre els obstacles o les facilitats que cada gènere té per sentir-se còmode realitzant-los. Així, d'una dona s'espera o pràcticament s'exigeix que siga atenta, tinga cura dels altres, mentre que un home resulta sospitós fent els mateixos gestos. D'aquesta manera, podem veure com l'estereotip femení està més a prop del reconeixement de la precariousness, tot i que també hi ha moltes formes femenines de negar-la, com preocupar-se només per la pròpia família, d'aquells que ens són pròxims, excloent els altres d'aquesta solidaritat. 
els nazis. ${ }^{28}$ Només ells eren sotmesos a aquest tipus de violència específica, a causa de la seua força física, que com a conseqüència dels estereotips s'associa amb la virilitat, el coratge i la duresa psicològica. Són els homes els que han d'enganyar als qui arriben als Lager, els que els duen fins les cambres de gas i també els qui han de traure els cossos i dur-los als crematoris. Són ells també els que han de tallar el cabell a les nouvingudes i els que es troben amb familiars o veïns, dels que saben quin serà el seu destí, però als que no ho poden dir. Són també els que saben que seran seleccionats, quan hagen estat mig any en aquest Kommando, per seguir el mateix camí que recorren diàriament, aquesta vegada per ser ells els qui perdran la vida a les cambres de gas. ${ }^{29}$

A banda d'aquest cas extrem, pot ser el més evident del dany específic contra els homes, hi ha d'altres que no per ser més subtils són menys dolorosos per als qui veuen ferida així la seua autoimatge. Aquest dany el podem veure ja amb la promulgació de les lleis de Nuremberg, ja que molts homes es quedaren sense feina per poder sustentar econòmicament a la família. L'home perdia així la possibilitat de complir amb el seu rol familiar segons l'ideal tradicional, el de ser qui sosté econòmicament als seus. Això va suposar una crisi d'identitat per a molts homes, ja que se sentiren perduts en no poder continuar complint aquest rol en què havien sigut educats. A més, amb el pas del temps i l'enduriment

28 "Haver concebut i organitzat els Escamots va ser el delicte més demoníac del nacionalsocialisme" (LeVI 20I I, 428)

${ }^{29}$ L'obra de Chil Rajchmann, Treblinka, dóna compte del tipus de vida a què estaven sotmesos els Sonderkommando d'aquest camp d'extermini on va estar deportat durant deu mesos. Quan arriba, l'assignen per classificar la roba dels que morien a la cambra de gas, roba entre la que troba la de la seua germana, de qui fou separat en la primera selecció només arribar al camp. Més endavant, el seleccionaren per tallar el cabell a les dones abans d'assassinar-les amb el gas, centenars de dones cada dia:

"Así pasan cientos de mujeres entre llantos y gritos y yo me transformo en un autómata demoníaco que les corta el pelo.

[...] Los asesinos nos obligan a cortar el pelo de nuestras hermanas unos minutos antes de morir, y nosotros, que tampoco nos queda mucho tiempo de vida, lo hacemos bajo el restallar del látigo. Nos han quitado todo raciocinio y no somos más que instrumentos de los criminales" (RACHJMAN 20I4, 47-8).

La tragèdia que suposa veure's sotmès al sistema concentracionari es veu reflectit al llarg de tota l'obra, ja que parla constantment de la seua necessitat, i la dels companys, de plorar, del perill de deixar-se perdre a causa de la tristesa, la incertesa de saber quan seran aniquilats ells també, amb la culpa de saber que, per sobreviure un poc més de temps, estan participant d'aquella maquinària exterminadora, veient com afusellen als companys i d'altres se suïciden. Tot i les condicions en què es trobava, Rajchmann participà de l'alçament de Treblinka, aconseguí fugir del camp a través d'un accidentat camí fins a Varsòvia, on s'amagà en un búnquer durant l'alçament general de Varsòvia, del que fou alliberat l'any 1945. En l'últim paràgraf de l'obra es qüestiona per què va sobreviure i l'única resposta que troba és: per donar testimoniatge de l'horror que es visqué a Treblinka i què succeí amb totes aquelles persones que perderen la vida en aquell camp. 
de les condicions socials per als jueus i la creació dels guetos, semblava que els homes eren els únics que corrien el risc de ser deportats per fer treballs forçats, ja que foren els primers en ser deportats, motiu pel qual molts es mantingueren amagats als guetos o fins $\mathrm{i}$ tot fugiren. Aquesta situació implicà que les dones hagueren de ser les sustentadores econòmiques i afectives de la família, ferint definitivament l'autoimatge dels homes, perquè es veien obligats a fugir deixant desemparada a la seua família.

A aquest dany inicial, cal afegir el que suposa per als homes d'una societat patriarcal les agressions sexuals i les violacions a les seues dones i familiars per part d'altres homes que tenen el poder. Com hem vist abans, el poder simbòlic que tenen associats aquests actes és molt poderós, ja que s'entenen com una ofensa personal cap a ells mateixos, perquè a més de ser incapaços de defensar a les seues dones, que és una de les principals funcions de l'home tradicional, aquestes han quedat deshonrades per sempre. Una resposta possible davant d'aquestes humiliacions és tornar el colp, tal com afirma haver actuat Jean Améry, tot i que en altres circumstàncies; colp que diu haver-li permès recuperar part de la seua dignitat. ${ }^{30} \mathrm{La}$ fortalesa física, les reaccions violentes, la manca de compassió... tots aquests elements que socialment s'han considerat associats a la virilitat masculina i al que suposa ser un home "com cal", són els que aprofitaren els SS per danyar l'autoimatge dels deportats, per ferir-los en la seua concepció com a éssers humans valuosos la vida dels quals paga la pena de ser viscuda.

\section{Testimoniar El GÈnere}

Memory is 'gendered' not only in terms of content but also with regard to processing mechanisms. For women victimized by the Nazis, 'memory' served as a source of identity preservation as well as a basic survival skill; concrete examples include the many reports of 'recipe exchanges', birthday celebrations and other

30 "En ese momento, lo sentí con una lucidez aguda, me tocaba avanzar un paso en mi largo proceso de apelación contra la sociedad. Rebelándome abiertamente, le devolví el golpe en el rostro: mi dignidad se estampó en forma de mamporro sobre su mandíbula - y el hecho de que, al final, fuera yo, corporalmente mucho más débil, quien sucumbiera y recibiera una buena paliza, no tuvo ya ninguna importancia. Apaleado y dolorido, estaba empero satisfecho conmigo mismo. Pero no por el coraje y el honor, sino sólo porque había comprendido bien que en la vida hay situaciones en que el cuerpo es todo nuestro yo y todo nuestro destino. Yo era mi cuerpo y nada más: en el hambre, en el golpe que recibí y en el golpe que devolví. Mi cuerpo, depauperado y encostrado de suciedad, era mi miseria. Mi cuerpo, cuando se extendía para asestar un puñetazo, era mi dignidad físico-metafísica. La violencia física, en situaciones como la mía, es el único medio para restablecer una personalidad dislocada. [...] Corroboré mi dignidad socialmente asestando un puńetazo contra el rostro de un ser humano" (АмÉRY 2013, 179). 
simple rituals upheld in the women's concentration camps. Women's memories appear to take shape, first and foremost, in the private rather than in the public sphere. Their memories are sooner rooted in the social minutiae of everyday life than in historical 'grand designs'. Yet the allegedly 'great debates' of history repeatedly focus on the latter (MusHABEN 2004, 170).

A partir del que hem analitzat fins ara, podem imaginar com seran de diferents els testimoniatges dels supervivents dels Lager depenent de quina és la relació que mantenen amb les exigències ideals de gènere que determina la norma reguladora de la societat en què es troben. Aquesta és una de les tesis fonamentals que vull defensar. De vegades aspectes merament formals suggereixen aquesta tesi, aspectes que podem dur a col-lació com a indici i símptoma, doncs mostren en l'aspecte formal una manera d'estar al camp i de relacionar-se amb aquesta experiència tràgica que es mostra diferent de la d'alguns homes. Un clar exemple d'açò és l'obra de L. Millu, Il fumo di Birkenau que consta de sis capítols, cadascun dels quals està dedicat a una companya que va perdre la vida en el camp. És un llibre que dóna testimoniatge del dany particular que sofriren persones properes a ella i de com la seua experiència al camp és inseparable de la vida (i la mort) de les seues companyes. Quelcom semblant fa Charlotte Delbo al tercer llibre de la seua trilogia Auschwitz et après, que du per títol Mesure de nos jours, on en cada capítol pren la veu una de les seues companyes supervivents del camp per donar compte de com va poder continuar endavant després de l'alliberament.

És en aquests testimoniatges on podem copsar realment la rellevància que les altres tingueren per a la supervivència als camps: el pas d'aquestes supervivents no es pot narrar si no donen compte dels vincles que establiren, de la protecció mútua, la cura i el suport físic i emocional que reberen de les companyes, de com aquests contactes donaven força per continuar endavant, per no donar-se per vençuda i continuar veient amb certa esperança el futur. És així com es crearen vincles com els de "germanes de camp" que rearticulen els vincles de parentiu, en termes de Butler en la seua obra Bodies that matter i les xarxes d'afectes que permetien una petita sensació de benestar tot i les condicions en què es trobaven: podien parlar de la seua vida passada, intercanviar receptes culinàries quan estaven famolenques, cantar cançons juntes, riure, i fins i tot compondre una obra de teatre (com va fer G. Tillion, Le Verfürbar aux enfers). Tots aquests gestos promovien la supervivència psicològica i social de les víctimes, de manera que les feia preservar la consciència de la seua humanitat i un sentit d'identitat personal tot i els mecanismes de deshumanització que hem estat veient.

Donar testimoniatge del vincle social establert en un Lager és un mètode més de resistència; una resistència, la d'aquestes dones, que va partir de la com- 
prensió de la dimensió activa de la vulnerabilitat com a generadora de capacitat d'agència. Això és, en tant que reconegueren la condició pròpia d'apertura al món i l'existència humana com a intrínsecament relacional, aquestes deportades entengueren que sols podrien sobreviure establint aquests vincles de suport mutu. En un context d'exclusió radical com són els camps de concentració i extermini, on es persegueix amb tota mena de mecanismes l'atomització de les víctimes, la despersonalització i el dany personal a l'autoimatge, la reivindicació de reprendre amb les companyes una vida en comú, on l'ajuda i el suport mutu, les relacions properes i afectives, continuen tenint espai és una mena de resistència que inicialment podria semblar inesperada i que en molts dels estudis tradicionals sobre Auschwitz ha passat desapercebuda però de la qual donen compte pràcticament totes les supervivents dels camps.

Sembla, però, que aquestes xarxes afectives i de suport mutu que tenen per origen gestos de proximitat (i no altres elements més polítics o de partit, com seria el cas de deportats polítics com Mercedes Núnez i Jorge Semprún) només es donaren en els camps de dones. El que he tractat d'esbossar en aquest text, i allò que resumiria la tesi que vull defensar, és una possible explicació d'aquest fet: en el context en què Auschwitz es va donar com un esdeveniment que canviaria la història de l'ésser humà, la societat heteronormativa i patriarcal assignava els valors de cura, suport mutu i ajuda a l'estereotip de gènere femení, de manera que el reconeixement de la precariousness és més propera a les dones i permet la creació de modes d'acció distints als que duen a terme els homes.

La relació entre el reconeixement de la vulnerabilitat i els modes feministes d'acció fou tractada explícitament per Butler en "Corporeal vulnerability, coalition and street policy", on trau a colllació l'exemple paradigmàtic de les mares de Plaza de Mayo a Buenos Aires. En aquest text, Butler desenvolupa la importància que "preserve the memory of the vulnerability of bodies requires a form of memorialization that must be repeated, and re-established over time and space" (ButLer 20i2, 178). Replega així la idea de Walter Benjamin de lliurar una batalla per la història dels oprimits perquè si no es cau en el risc que aquesta desaparega en l'oblit. Aquesta batalla cal lliurar-la socialment mantenint i transmetent la veu dels oprimits, dels emmudits, i això és el que vull fer en aquest text donant veu a les víctimes de situacions extremes de dany, i també el que feren i fan les Mares de Plaza de Mayo des de 1977.

Les mares ${ }^{31}$ es reuneixen des de fa més de quaranta anys tots els dijous davant de la Casa Rosada del govern argentí per protestar públicament per la desaparició dels seus fills durant l'última dictadura. Decidiren unir-se i recla-

31 "Fuimos las mujeres porque los maridos... es peligroso" (Las viejas, 20 I 4, 53). 
mar totes juntes, perquè sabien que cadascuna per separat no tindria ressò: "Juntas podemos llegar a hacer algo, separadas nada" (Las viejas, 2014, 54). Entengueren que el seu objectiu ja no era trobar el seu propi fill, sinó els de totes, no es tractava d'una lluita individual o personal, sinó que era i havia de ser col-lectiva. Aquesta lluita col-lectiva atorgà sentit de comunitat i esperança a les dones que participaven, les feia sentir que no estaven soles i cada vegada que es reunien retrobaven l'alegria i el benestar de sentir-se part d'una reivindicació que les superava personalment però que les incloïa a totes en el seu dany:

Por eso siento tanto orgullo de haber estado con esas mujeres, te juro por Dios que lo más grande que me pasó en la vida después de haber parido a mis dos hijos fue estar con esas madres. Por el valor, por el coraje que tuvieron, por la dignidad, por la limpieza, por la pureza que tuvieron (Las viejas, 2014, 63).

Aquestes manifestacions, que sempre foren i segueixen sent pacífiques, ${ }^{32}$ començaren sent il.legals i la seua organització, clandestina, però el que volien era recuperar l'espai públic perquè es coneguera la seua situació i els donaren alguna explicació de què havia succeït amb els seus fills. Desafiaren al règim dictatorial, no sense conseqüències ni por, ja que moltes d'elles foren també segrestades i amenaçades per la policia. La seua era una protesta contra la brutalitat i perquè es fera justícia, i actualment continua sent un reclam de fer justícia contra tots els que participaren d'aquestes tortures i assassinats, i contra l'oblit.

Suffering, memorialisation and political resistance mark that ongoing and periodic public demonstration, and yet, it is also a demonstration that claimed public space when it was forbidden, and claims it still, maintaining it as a political right (ButLer 20 I 2, 179).

La receptivitat al que succeeix és també funció i efecte de la vulnerabilitat, diu Butler, ja que implica ser receptius a una història que un altre cos ha sofert o està sofrint en l'actualitat, de manera que es tractaria d'una empatia que es deriva d'una apertura a uns altres cossos, d'una apertura als altres, estiguen aquests presents o només narrats, sent així una empatia a través del temps. Aquesta és una altra manera d'entendre que els cossos no són unitats tancades o estanques en un espai i un temps, sinó que mitjançant la receptivitat

32 "Siempre dentro de los cánones no violentos, nunca se nos pasó por la cabeza enfrentar al enemigo con las mismas armas que usaba, siempre dentro de parámetros pacíficos. El riesgo era el mismo, el enemigo era el mismo. Pero dio otro resultado que no se esperaba, será porque se usó otro método que no era el usual en luchas sociales y políticas, otra forma de enfrentar el problema. Pero costoso era" (Las viejas, 20I4, 84). 
podem entendre el cos com un espai on es poden transmetre els records dels altres, convertint-se així en "the body is a point of transfer (and transitivity) in which your history becomes mine, or where your history passes through mine" (BUTLER 2OI2, 181).

És gràcies a la interconnexió entre els diferents individus com es pot transmetre la memòria mitjançant la transitivitat del record. És aquesta la forma que tenim aquells que no fórem testimonis directes de donar compte dels fets que ocorregueren en el passat i que corren el perill de perdre's en l'oblit. És clar que aquest tipus de transmissió mai no podrà podrà ser del mateix tipus que el testimoniatge de les víctimes, però la interdependència que ens constitueix en tant que éssers humans permet que el nostre cos, la nostra veu, siga vehicle d'aquests records que ens constitueixen com el que som actualment.

L'escolta atenta de l'altre, ${ }^{33}$ doncs, serà essencial perquè la interpel.lació afectiva que busca dur a terme el relat del que visqué la víctima siga efectiu. La intervenció ètica i política del relat del supervivent només és possible si la societat en què es realitza tal acte de parla es fa càrrec de la història que està ficant al seu abast des del dolor més íntim. És per això que, de vegades, s’ha interpretat el testimoniatge com una "donació"; una donació, però, que necessita ser acceptada per a poder funcionar com a tal. Aquesta escolta atenta del que ens vol transmetre la víctima suposa fer atenció no només a què diu sinó a com es diu, a la tensió que habita el seu cos mentre rememora els fets i, sobre tot, suposa una disposició d'apertura afectiva cap a la víctima. Sols mitjançant aquesta apertura podrem copsar les distintes maneres de dir i de mirar dels diferents supervivents $i$ atendre a la singularitat de les seues experiències personals.

33 "I el testimoniatge, quan l'antic deportat sap que, si no és comprés, almenys sí veritablement escoltat, li ret la seua dignitat, en la mateixa mesura en què la seua identitat ha estat humiliada: aquella d'antic deportat o del qui ha fugit dels guetos" (WIEviorkA 20I3, 161, la traducció és meua). 


\section{BIBLIOGRAFIA}

Agamben, G. 2000, Homo sacer. III. Lo que queda de Auschwitz. El archivo y el testigo, València: Pre-Textos.

AmÉRY, J. 20 I 3, Más allá de la culpa y la expiación: Tentativas de superación de una víctima de la violencia, València: Pre-Textos.

Antelme, R. 200 I, La especie humana, Madrid: Arena Libros.

ArfuCh, L. 20 I 8, La vida narrada: memoria, subjetividad y politica, Villa María: Eduvim.

Batalla, A. 20I7, "Viure per testimoniar. L'exemple de Primo Levi", en Mirades intersubjectives en la filosofia actual, València: Societat de Filosofia del País Valencià.

Bernárdez, A., García, I. i González, S. 2008, Violencia de género en el cine español: análisis de los años 1998 a 2002 y guia didáctica, Madrid: Editorial Complutense.

Buber-Neumann, M. 2005, Prisionera de Stalin y Hitler, Barcelona: Galaxia Gutenberg.

Butler, J. I990, Gender Trouble: Feminism and the Subversion of Identity, Londres: Routledge.

Butler, J. 2004, Precarious life. The powers of mourning and violence, Londres: Verso.

Butler, J. 2009, Frames of war. When is Live Grievable?, Londres: Verso.

Butler, J. 20I I, Bodies that matter, Londres: Routledge.

Butler, J. 20 I 2, "Corporeal vulnerability, coalition and street policy", en The State of Things, Londres: Koenig Books.

Copelon, R. 1994, "Surfacing Gender: Re-Engraving Crimes Against Women in Humanitarian Law", Hastings Women's Law Journal, 5 (2): 243-66.

Delbo, C. 2004, Auschwitz y después, vol. 1, 2 i 3, Madrid: Turpial.

Forges, J. F. 2006, Educar contra Auschwitz. Historia y memoria, Barcelona: Anthropos.

Kellenbach K. Von (2004). God's Love and women's Love. Prision chaplains counsel. The wives of Nazi perpetrators. Journal of Feminist Studies in Religion, vol. $20, \mathrm{n}^{\circ} 2$.

KLÜger, R. 1997, Seguir viviendo, Barcelona: Galaxia Gutenberg.

LeVI, P. 20 I I, Trilogia d'Auschwitz, Barcelona: Edicions 62.

Loridan-Ivens, M. 20 I 5, Y tú no regresaste, Barcelona: Salamandra.

Madres de Plaza de Mayo. Línea fundadora 20I4, Las viejas, Buenos Aires: Marea editorial.

Millu, L. 2019, El humo de Birkenau, Barcelona: Acantilado. 
Mushaben, J. M. 2004, "Memory and the Holocaust: processing the past through a gendered lens", History of the human sciences, August 1, 17 (2-3): 147-85

Rajchmann, C. 20I4, Treblinka, Barcelona: Seix Barral.

Ramos González, A. 20 Io, "Cuando sus cuerpos se hicieron humo: Lo indecible de la Shoá a través de los textos literarios femeninos", Revista Chilena de Literatura, 76: 257-78.

SAnfilippo, M. 20I I, "Memorias de Birkenau en la literatura italiana: Bruck, Millu, Nissim, Sonnino y Tedeschi”, en Almela, M., García Lorenzo, M., Guzmán, H. i SAnfilippo, M. (coord.), Los ecos de la memoria, Madrid: UNED.

Semprún, J. 2013, La escritura o la vida, Barcelona: Tusquets.

Strejilevich, N. 20 I9, Un día, allá por el fin del mundo, Santiago: LOM ediciones. Wieviorka, A. 2013, L'ère du témoin, París: Pluriel. 